\title{
Placenta diagnostic in human medicine: what is possible, what is necessary?
}

\author{
Andrea Tannapfel \\ Institute of Pathology, Medizinische Fakultät, University of Leipzig, Germany
}

\begin{abstract}
Summary
The importance of human placental examination is often underestimated, not only by the gynecologists or pediatricians, but also by the pathologists. The examination of a diseased or dead fetus is inadequate without examination of its most accessible organ, the placenta. The placenta is readily available for study, and its examination may provide significant information relating to intrauterine or perinatal death, intrauterine growth retardation, malformations or infections. Unlike more static tissues, the placenta undergoes a series of morphologic changes during its short life span, making an understanding of the normal more difficult. Appreciation of pathological changes demands a knowledge of normal structure and development. In the following pages, the normal placenta will therefore also be described as well as macroscopic and microscopic diagnostic features.
\end{abstract}

Keywords: $\quad$ human, placenta, physiology, pathology

Plazentadiagnostik in der Humanmedizin: Was ist möglich, was ist nötig?

Die histopathologische Untersuchung der Plazenta wird in ihrer klinischen Relevanz häufig unterschätzt. Die Beschreibung der krankhaften Veränderungen der Plazenta („Plazentopathien“) ist unverzichtbarer Bestandteil der Aufklärung möglicher Abortursachen. Generell wird zwischen Wachstumsstörungen, Reifungsstörungen, Entzündungen und Durchblutungsstörungen unterschieden. Die Diagnostik von Plazentopathien erfordert die Kenntnis der regelhaften Morphologie der Plazenta, die während der Schwangerschaft mehrfachen Gestaltsänderungen unterliegt. Daher soll im folgenden kurz auf die physiologische Plazentaentwicklung eingegangen werden, bevor die relevanten Plazentopathien beschrieben werden.

Schlüsselwörter: Mensch, Plazenta, Physiologie, Pathologie

\section{Introduction}

Examination of the placenta can yield information that may be important in the immediate and later management of mother and infant. This information may also be essential for protecting the attending physician in the event of an adverse maternal or fetal outcome.

Generally, pathologists argue that all placentas should be examined by a pathologist, however, most hospitals do not mandate this examination. Instead, the delivering physician is usually responsible for determining when pathologic interpretation is necessary (as determined by the American Academy of Familial Physicians). The examination of normal placentas and most abnormal placentas can be accomplished within one minute. Universal examination of the placenta by a pathologist, with histopathological documentation of findings based on abnormal appearance or certain clinical indications, is standard medical practice.

\section{Clinical Characteristics of the Normal Placenta}

The usual term placenta in humans is about $22 \mathrm{~cm}$ in diameter and 2.0 to $2.5 \mathrm{~cm}$ thick. It generally weighs approximately 500 g. However, the measurements can vary considerably, and placentas generally should be weighed in the delivery room. The maternal surface of the placenta should be dark maroon in colour and divided into lobules or cotyledons. The structure should appear complete, with no missing cotyledons. The fetal surface of the placenta should be shiny, grey and translucent enough that the colour of the underlying maroon villous tissue may be seen. At term, the typical umbilical cord is 55 to $60 \mathrm{~cm}$ in length, with a diameter of 2.0 to $2.5 \mathrm{~cm}$. The structure should have abundant Wharton's jelly, and no true knots or thromboses should be present. The total cord length should be estimated in the delivery room, since only the delivering physician has access to both the placental and fetal ends.

The fetal membranes are usually grey, wrinkled, shiny and translucent. The membranes and the placenta have a distinctive metallic odour that is difficult to describe but is easily recognized with experience. Normally, the placenta and the fetal membranes are not malodorous.

The following diagnostic work-up of the placenta is divided into two parts:

The description of the gross morphology (macroscopy) is starting shortly after birth. The placenta should be inspected after delivery within the delivery room. The second part, the microscopical examination, takes place after dissecting and paraffin-embedding of the placental tissue (Gersell and Krauss 1994).

\section{Macroscopic examination of the placenta}

Evaluating placental completeness is of critical, immediate importance in the delivery room. Retained placental tissue is associated with postpartum hemorrhage and infection. 
The maternal surface of the placenta should be inspected to be certain that all cotyledons are present. All or part of the placenta is retained in placenta accreta, placenta increta and placenta percreta. In these conditions, the placental tissues grow into the myometrium to lesser or greater depths. Manual exploration and the removal of retained placental tissue are necessary in these cases. The placental size is also important to be inspected in the delivery room. Placentas less than $2.5 \mathrm{~cm}$ thick are associated with intrauterine growth retardation of the fetus. Placentas more than $4 \mathrm{~cm}$ thick have an association with maternal diabetes mellitus, fetal hydrops (of both immune and nonimmune etiology) and intrauterine fetal infections. An extremely thin placenta may represent placenta membranacea. Placenta membranacea is associated with a very poor fetal outcome.

The recognition of the placental shape is also an important diagnostic issue which should be performed immediately after birth. Extra placental lobes are substantial, primarily because they may lead to retained placental tissue. The dimensions and volume of the placenta should be estimated.

The inspection of the placental consistency and surfaces is a part of the immediate diagnosis.

The placenta should be palpated, and the fetal and maternal surfaces should be carefully examined. In a term infant without anemia, the maternal surface of the placenta should be dark maroon. In a premature infant, the placenta is lighter in colour. Pallor of the maternal surface indicates the presence of fetal anemia, which may be a sign of hemorrhage.

A thick ring of membranes on the fetal surface of the placenta may represent a circumvallate placenta, which is associated with prematurity, prenatal bleeding, abruption, multiparity and early fluid loss. Numerous small, firm, white, grey or yellow nodules on the fetal surface may represent amnion nodosum which is associated with oligohydramnios, renal agenesis and poor fetal outcome.

A diffusely soft placenta may represent infection, particularly if the structure is also thickened. Firm areas in the placenta may represent fibrin deposition or infarction. Fresh infarcts are red, while older infarcts are grey. Fibrin deposits are grey and, if extensive, may be associated with intrauterine growth retardation and other poor fetal outcomes. If infarcts or fibrin occupy less than five percent of the placental mass, they are usually unimportant.

Focal fleshy, dark-red areas may represent chorioangiomas. These benign hemangiomas occur in one percent of all placentas. While small chorioangiomas are usually of no clinical significance, large chorioangiomas are associated with fetal anemia, thrombocytopenia, hydrops, hydramnios, intrauterine growth retardation, prematurity and stillbirth.

Gestational trophoblastic neoplasia, including benign hydatidiform moles, invasive moles and choriocarcinoma, only rarely coexist with viable gestations. Moles appear as grape-like clusters of edematous villi, while choriocarcinoma may look much like an infarct (Kraus 1991).

\section{Umbilical Cord}

While opinions of authorities differ with regard to the limits of normal for cord length, 40 to $70 \mathrm{~cm}$ would appear to be a reasonable range. In part, cord length is genetically determined. Short cords may result in cord rupture, hemorrhage and stricture. Cords of insufficient length may also result in breech and other fetal malpresentations, a prolonged second stage of labour, abruption and uterine inversion (Fox 1978).

\section{Histopathological examination of the placenta}

The second part of the placenta diagnostic, the microscopical evaluation, takes place after dissecting the placenta and paraffinembedding of the tissue.

Inflammation and infection of the placenta and the fetus are the most common and most important placental pathology. The placenta and the fetus are infected via two major pathways: (1) the ascending, amniotic (transcervical) route and (2) the hematogenous (transplacental) route. In ascending infection, micro-organisms produce an acute inflammatory reaction in the fetal membranes (chorioamnionitis), the umbilical cord (funisitis), and ultimately the fetus itself. The etiologic agents usually are bacterial, but fungi and possibly viruses are involved. In hematogenous infections, the infectious agent produces an inflammatory response in the villi (villitis) and the intervillous space. Viruses are believed to be the most common agents involved, but some bacterias (spirochetes) and protozoa (Toxoplasma gondii) also infect the placenta in this manner. A third important route by which infections may reach the fetus is during passage through an infected birth canal (intrapartum infection). The placenta, of course, is not involved in this process (Benischke and Kaufmann 1995).

Bacterial infection: The most common bacteria include gramnegative rods, gram-positive rods (listeria) and cocci as well as fusobacteria. Each bacterium produces characteristic changes in gross and microscopic examination which can be diagnosed. Viral infections: CMV placentitis is the most commonly identified of all placental infections. The prevalence of congenital infections ranges from 0.2 to $2.2 \%$ among all live births. Further viruses which may cause placentitis are HSV, Parvovirus [B 19], E-BV, as well as varicella and rubella (Tondury and Smith 1966).

Fungal infections caused by candida, coccidioidomycosis and cryptococcosis are rare, but may occur.

Other infections are syphilis, toxoplasmosis, malaria, and trichomoniasis. Although potentially catastrophic, feto-placental infections caused by virus and bacteria are infrequent. Far more commonly, a focal chronic villitis, for which no etiology can be established, is discovered incidentally in sections of the placenta. Estimates of the phenomenon varies greatly. Villitis of unknown etiology (VUE) may be detected in about $12 \%$ of all placentas examined (Altshuler 1977, Redline and Abramowsky 1985).

Circulatory disorders are also common features of the placenta pathology. An infarct, as in other organs, is an area of ischemic necrosis resulting from obstruction of its blood supply. The villi are sustained by the oxygen and nutrients supplied by the maternal blood in the intervillous space and that most infarcts are due to occlusion of the maternal uteroplacental vessels. Infarcts are common and occur in about 25\% of otherwise normal term placenta. The finding of an infarct of less than $5 \%$ of the villous parenchyma in an otherwise normal placenta is of 
no clinical significance. Extensive placental infarction is associated with fetal hypoxia, intrauterine growth retardation, and fetal death in utero (Altshuler 1984, Rayne and Kraus 1993).

\section{Literature}

Altshuler G. (1977): Placentitis, with a new light on and old torch Obstet Gynecol Annu 6, 197-221.

Altshuler G. (1984): Chorangiosis. Arch Pathol Lab Med 108: 71-74. American Academy of Family Physicians (1998): Examination of the placenta.

Benirschke K. and Kaufmann P. (1995): Pathology of the human placenta, 3rd. ed. Hamburg, Berlin, Heidelberg, Springer.

Fox H. (1978): Pathology of the placenta. Major problems in Pathology, Vol 7. Philadelphia, WB Saunders.

Gersell D.J. and Kraus F.T. (1994): Diseases of the Placenta. In: Kurman RJ (ed) Blaustein's: Pathology of the Female Genital Tract. 4rd. ed. Hamburg, Berlin, Heidelberg, Springer. 975-1048.

Kraus F.T. (1991): Role of the pathologist in evaluation of infertility: Current practise and future developments. In: Kraus FT, Damjanov I,
Kaufman N (eds) Pathology of the Reproductive Failure. Baltimore, Williams and Williams, 339-250.

Rayne S.C. and Kraus F.T. (1993): Placental thrombi and other vascular lesions. Classification, morphology, and clinical correlation. Path Res Pract 189, 2-17.

Redline R.W. and Abramowsky C.R. (1985): Clinical and pathologic aspects of recurrent placental villitis. Hum Pathol 16: 727-731.

Tondury $G$ and Smith D.W. (1966): Fetal rubella pathology. J Pediatr 68, 867-879.

PD Dr. med. Andrea Tannapfel

Institute of Pathology

University of Leipzig

Liebigstraße 26

04103 Leipzig

Tel.:03419715036

e-mail: tana@server3.medizin.uni-lepipzig.de 